Louisiana State University

LSU Digital Commons

$9-1-2017$

\title{
Plant genotype and induced defenses affect the productivity of an insect-killing obligate viral pathogen
}

Ikkei Shikano

Pennsylvania State University

Elizabeth M. McCarthy

Indiana University Bloomington

Bret D. Elderd

Louisiana State University

Kelli Hoover

Pennsylvania State University

Follow this and additional works at: https://digitalcommons.Isu.edu/biosci_pubs

\section{Recommended Citation}

Shikano, I., McCarthy, E., Elderd, B., \& Hoover, K. (2017). Plant genotype and induced defenses affect the productivity of an insect-killing obligate viral pathogen. Journal of Invertebrate Pathology, 148, 34-42. https://doi.org/10.1016/j.jip.2017.05.001

This Article is brought to you for free and open access by the Department of Biological Sciences at LSU Digital Commons. It has been accepted for inclusion in Faculty Publications by an authorized administrator of LSU Digital Commons. For more information, please contact ir@lsu.edu. 


\title{
Plant genotype and induced defenses affect the productivity of an insect- killing obligate viral pathogen
}

\author{
Ikkei Shikano ${ }^{\mathrm{a}, *}$, Elizabeth M. McCarthy ${ }^{\mathrm{b}}$, Bret D. Elderd ${ }^{\mathrm{c}}$, Kelli Hoover ${ }^{\mathrm{a}}$ \\ a Department of Entomology and Center for Chemical Ecology, Pennsylvania State University, University Park, PA 16802, USA \\ b Department of Chemistry, Indiana University, Bloomington, IN 47404, USA \\ c Department of Biological Sciences, Louisiana State University, Baton Rouge, LA 70803, USA
}

\section{A R T I C L E I N F O}

\section{Keywords:}

Biological control

Epizootic

Glycine max

Parasite fitness

Spodoptera frugiperda multiple nucleocapsid

nucleopolyhedrovirus

Tritrophic interaction

\begin{abstract}
A B S T R A C T
Plant-mediated variations in the outcomes of host-pathogen interactions can strongly affect epizootics and the population dynamics of numerous species, including devastating agricultural pests such as the fall armyworm. Most studies of plant-mediated effects on insect pathogens focus on host mortality, but few have measured pathogen yield, which can affect whether or not an epizootic outbreak occurs. Insects challenged with baculoviruses on different plant species and parts can vary in levels of mortality and yield of infectious stages (occlusion bodies; OBs). We previously demonstrated that soybean genotypes and induced anti-herbivore defenses influence baculovirus infectivity. Here, we used a soybean genotype that strongly reduced baculovirus infectivity when virus was ingested on induced plants (Braxton) and another that did not reduce infectivity (Gasoy), to determine how soybean genotype and induced defenses influence OB yield and speed of kill. These are key fitness measures because baculoviruses are obligate-killing pathogens. We challenged fall armyworm, Spodoptera frugiperda, with the baculovirus $S$. frugiperda multi-nucleocapsid nucleopolyhedrovirus (SfMNPV) during short or long-term exposure to plant treatments (i.e., induced or non-induced genotypes). Caterpillars were either fed plant treatments only during virus ingestion (short-term exposure to foliage) or from the point of virus ingestion until death (long-term exposure). We found trade-offs of increasing OB yield with slower speed of kill and decreasing virus dose. OB yield increased more with longer time to death and decreased more with increasing virus dose after short-term feeding on Braxton compared with Gasoy. OB yield increased significantly more with time to death in larvae that fed until death on non-induced foliage than induced foliage. Moreover, fewer OBs per unit of host tissue were produced when larvae were fed induced foliage than non-induced foliage. These findings highlight the potential importance of plant effects, even at the individual plant level, on entomopathogen fitness, which may impact epizootic transmission events and host population dynamics.
\end{abstract}

\section{Introduction}

Changes in plants induced by microbes and/or insect herbivores can have profound effects on the interactions between the three participants, shaping their abundances and community structure (Biere and Bennett, 2013; Biere and Tack, 2013; Shikano et al., 2017a). Insectassociated microbes, whether in the gut or outside the insect body, can influence tritrophic interactions by aiding insect detoxification of phytochemicals (Adams et al., 2013; Hansen and Moran, 2014; Mason et al., 2014), enabling insects to manipulate plant physiology for their own benefit (Chung et al., 2013; Frago et al., 2012) and providing insects with essential nutrients that are unavailable in their host plants (Douglas, 2015; Hansen and Moran, 2014). Phytopathogens and soil-borne microbes can induce changes in plants that positively or negatively influence insect herbivores, through direct or indirect plantmediated effects on the insects (Pineda et al., 2010; Tack and Dicke, 2013). Similarly, entomopathogenic fungi can endophytically colonize plants and influence plant-insect interactions potentially by changing plant defenses and growth (Ownley et al., 2010). Insect-induced changes in plants can also strongly influence the interactions between plants, insects and their pathogens (Cory and Hoover, 2006).

The ability of insect pathogens to infect their hosts is affected by variation in plant quality, both between and within plant species (Cory and Hoover, 2006). The forest tent caterpillar, Malacosoma disstria, was as much as 100 -fold more resistant to the bacterium Bacillus thuringiensis when exposed to the bacterium on foliage of quaking aspen, Populus tremuloides, than sugar maple, Acer saccharum (Kouassi et al., 2001). Mortality in greenhouse whitefly, Trialeurodes vaporariorum, nymphs

\footnotetext{
* Corresponding author at: 501 ASI Building, University Park, PA 16803, USA

E-mail address: ius15@psu.edu (I. Shikano).
} 
were significantly higher when conidial suspensions of the pathogenic fungi Beauveria bassiana and Isaria fumosoroseus were applied to cucumber plants than to tomato plants (Poprawski et al., 2000). Mortality induced by baculoviruses can also vary with the quality of the foliage ingested along with the virus, such as the variation in quality between plant species (Ali et al., 1998; Farrar and Ridgway, 2000; Hoover et al., 1998a; Keating et al., 1988), different parts within a plant (Ali et al., 1998), plant phenology (Raymond and Hails, 2007), and defensive status of the plant (i.e., constitutive vs. herbivore-induced) (Elderd et al., 2013; Hoover et al., 1998a; Shikano et al., 2017b).

While numerous studies have demonstrated plant-mediated effects on pathogen-induced mortality, several other factors can influence the population dynamics of insects and their pathogens. There are four basic population parameters that are fundamental to pathogen fitness: transmission, speed of kill, yield (number of infectious stages released from a single host) and persistence (the rate of loss of infectious stages from the environment) (Anderson and May, 1981; Raymond et al., 2005, 2002). The few studies that examined plant-mediated effects on pathogen yield focused primarily on baculoviruses (Ali et al., 2002; Cory and Myers, 2004; Hodgson et al., 2004, 2002; Raymond et al., 2002; Raymond and Hails, 2007).

Baculoviruses are food-borne insect pathogens with narrow host ranges that can cause epizootics in outbreak host populations (Cory and Myers, 2003). They are obligate pathogens, and those that infect lepidopteran insects must kill their hosts to release orally infectious stages (viral occlusion bodies; OBs) to infect new hosts. To ensure that infection occurs via horizontal transmission, a lethal dose of OBs must be consumed along with the leaf tissue on which it resides. The amount of virus that a host yields after death depends, in part, on the leaf tissue and its phytochemistry. Differential OB yields have been demonstrated with short-term feeding on different plant species at the point of virus ingestion (immediately before, during and immediately after virus exposure) (Cory and Myers, 2004; Raymond et al., 2002) and longterm feeding on different plant species, parts and host phenology (either throughout larval development or during and after viruschallenge until host death) (Ali et al., 2002; Hodgson et al., 2004, 2002; Raymond and Hails, 2007).

We recently demonstrated that short-term feeding by fall armyworms, Spodoptera frugiperda, at the point of virus ingestion on soybean leaf disks exhibiting induced anti-herbivore resistance, reduced levels of mortality caused by a baculovirus $S$. frugiperda multi-nucleocapsid nucleopolyhedrovirus (SfMNPV) compared to short-term exposure to non-induced leaf disks, though the speed of kill was not affected (Shikano et al., 2017b). The degree to which soybean induced resistance lowered baculovirus-induced mortality varied strongly among eight soybean genotypes (Shikano et al., 2017b). Here, we selected two soybean genotypes from our previous study, one genotype that strongly reduced lethal infection by baculovirus when induced (Braxton genotype) and another that did not have this effect (Gasoy genotype). Although records of SfMNPV epizootics in fall armyworms on soybean plants are not available, SfMNPV is known to cause epizootics in fall armyworms in pastures (Fuxa, 2004). We used the intraspecific variation in soybean-mediated effects on SfMNPV efficacy as a model system to examine how this variation may influence virus productivity. Our objectives were to determine if virus yield would be influenced by short-term exposure to different soybean genotypes and to induced and non-induced foliage, and whether long-term feeding on induced and non-induced foliage from the Braxton genotype (from virus ingestion until death) would affect virus yield. Since Braxton and Gasoy genotypes varied in defensive chemistry (phenolic content and peroxidase activity) and in their effects on fall armyworm feeding and growth, particularly when the plants were induced (Shikano et al., 2017b), we hypothesized that virus yield will be differentially affected by short-term exposure to the two plant genotypes and to induced or non-induced foliage. We also hypothesized that long-term feeding on induced soybean foliage will result in larvae producing fewer OBs at death than on non-induced foliage, in part because induced soybean defenses significantly inhibit fall armyworm growth (Shikano et al., 2017b) and smaller hosts tend to produce less virus OBs (Wilson et al., 2000). Reduced OB yield on induced foliage might also result from increased susceptibility of infected fall armyworms to induced soybean defensive chemicals, because baculovirus infection can cause a downregulation of genes involved in detoxification and digestive function (Noland et al., 2013). Thus, infected armyworms on induced foliage may exhibit faster death than those on non-induced foliage and consequently yield fewer OBs, which is typical of the trade-off between speed of kill and OB yield exhibited by baculoviruses (e.g. Wilson et al., 2000; Redman et al., 2016).

\section{Materials and methods}

\subsection{Plants and jasmonic acid application}

Soybean, Glycine max (Fabaceae), seeds were obtained from the National Plant Germplasm System, United States Department of Agriculture Agricultural Research Service (USDA-ARS). Plants were grown in professional growing mix (Sunshine Mix 4 Aggregate Plus) in $10 \mathrm{~cm}$ plastic pots in a temperature-controlled greenhouse at $25^{\circ} \mathrm{C}$ and 16L:8D supplemented with high pressure sodium lights. Plants were watered every two days, and fertilized with $3 \mathrm{~g}$ of Osmocote Plus (15-912; Scotts) when the first true leaves were fully expanded. For each experiment, 40-60 plants of each genotype were grown and randomly divided into an equal number of induced or non-induced treatments.

Gasoy 17 and Braxton genotypes were selected based on qualitative differences in jasmonic acid (JA)-induced resistance against fall armyworms and differential effects of JA-induced defenses on baculovirus efficacy (Shikano et al., 2017b). Both genotypes are from soybean maturity group VII and have determinate stem termination. Plants were exogenously sprayed with JA, as described in Shikano et al. (2017b). JA is a phytohormone that upregulates plant defenses against chewing herbivores (Thaler et al., 1996). Control plants were sprayed with the same concentration of the carrier solution. Plants were used in bioassays $48 \mathrm{~h}$ after JA application. Only the youngest, fully opened trifoliate leaf was used and cork borers were used to cut leaf disks $\left(0.64 \mathrm{~cm}^{2}\right)$ for the experiments described below.

\subsection{Insects and baculovirus}

Newly molted fourth instar fall armyworm, $S$. frugiperda, were used in all experiments. The rationale for using fourth instars is provided in Elderd and Reilly (2014). To explain briefly, the initial infections before an epizootic typically occur in first instar larvae, which is the most susceptible age, through horizontal or vertical transmission. By the time infected first instars die (4-6 days) and release OBs, uninfected larvae have developed to approximately the fourth instar. Since infected fourth instars produce exponentially more OBs than infected first instars, fourth instars were the focus of this study. Eggs were obtained from Benzon Research (Carlisle, PA, USA) and larvae were reared on artificial diet (Southland Products Inc., Lake Village, AR, USA) at $29^{\circ} \mathrm{C}$ and 16L:8D in 128-well insect rearing trays (Frontier Agricultural Sciences, Newark, DE, USA) until head capsule slippage in the late third instar. These larvae were transferred to individual wells of a 12well cell culture plate without food to complete their molt. Larvae were individually weighed to the nearest $0.1 \mathrm{mg}$ before use in the experiments.

Wild-type SfMNPV-B (Nicaragua) occlusion bodies (OB) were obtained from Dr. James Slavicek, USDA Forest Service (Delaware, $\mathrm{OH})$. OBs were quantified under a phase contrast microscope using an improved Neubauer brightline haemocytometer. 


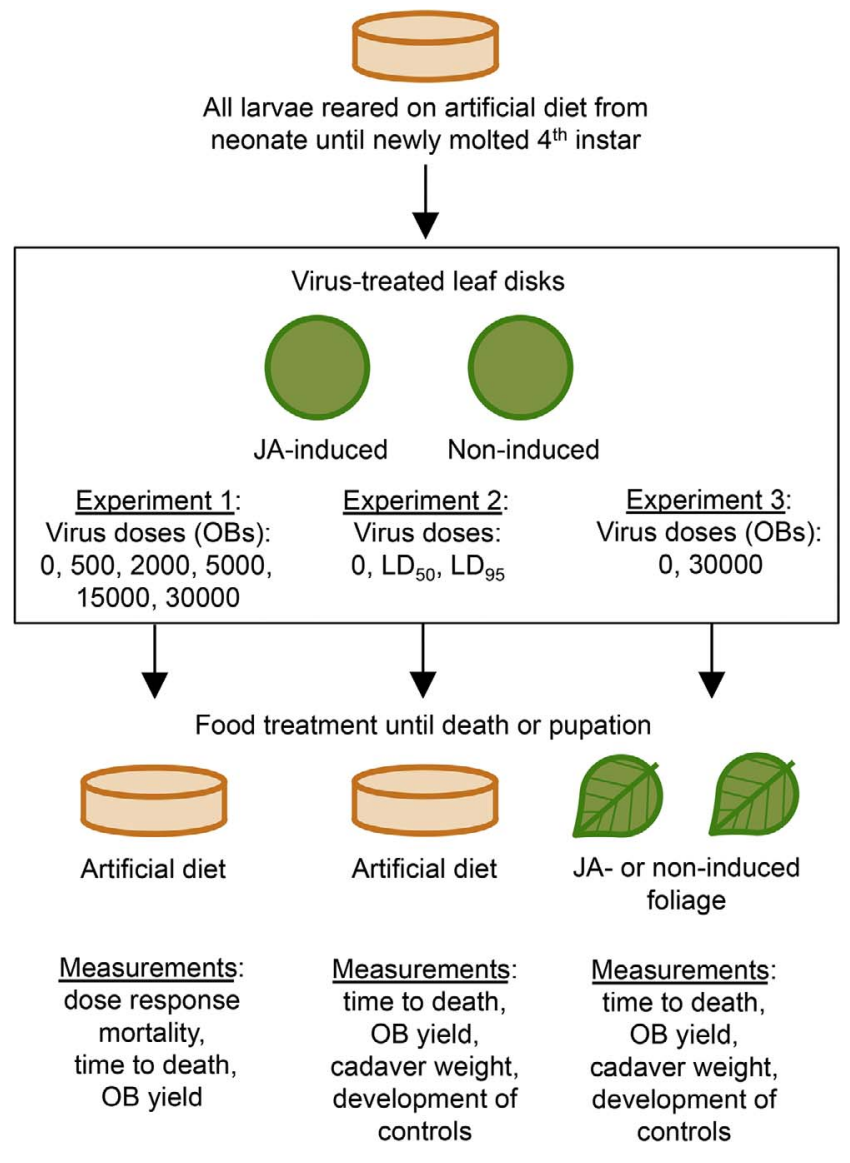

Fig. 1. Diagram illustrating the designs of the three experiments, including the virus doses used, the food treatments post virus-challenge and recorded measurements.

\subsection{Experiment 1: Effects of short-term feeding on plants of different} quality during virus-challenge on baculovirus infectivity and $O B$ production

Please see Fig. 1 for a flowchart of the three experiments described below. To determine the effects of constitutive and JA-induced soybean defenses on baculovirus infectivity and OB production, larvae ingested foliage and virus at the same time, but consumed artificial diet before and after virus-challenge. We challenged the larvae with SfMNPV as described in Shikano et al. (2017b). Briefly, comparable numbers of leaf disks were removed from each Braxton and Gasoy plant, which had been JA- or control-treated, and equally distributed to each virus dose. There were 30 leaf disks per dose for each induction treatment per genotype. Leaf disks were kept moist on wet paper towels. A $2 \mu \mathrm{l}$ droplet of Milli-Q water containing one of five doses of SfMNPV (500, $2000,5000,15,000,30,000$ OBs) was applied to each leaf disk. Control disks were treated with just Milli-Q water. Once the droplet dried completely, one leaf disk was presented to a single larva in individual wells of a 12-well cell culture plate. Each well was lined with moist filter paper and a moist paper towel was placed under the lid of the plate to keep the leaf disk and insect from desiccating. The plate was maintained at $29^{\circ} \mathrm{C}$ and $16 \mathrm{~L}: 8 \mathrm{D}$ for $20 \mathrm{~h}$. Larvae that consumed the entire leaf disk were transferred to individual $30 \mathrm{ml}$ plastic containers with ad libitum artificial diet until death or pupation. Mortality was recorded every $8 \mathrm{~h}$.

Cadavers were collected immediately upon death in individual $1.5 \mathrm{ml}$ centrifuge tubes. Moribund larvae that had stopped feeding were also collected and maintained at $29^{\circ} \mathrm{C}$ until death. The tube was kept ventilated by placing a small piece of Kimwipe under the lid. All cadavers were stored at $-20^{\circ} \mathrm{C}$. Six cadavers liquefied over the diet before they could be collected, and were included in the time to death analysis but excluded from the $\mathrm{OB}$ yield analysis. To determine the numbers of OBs produced in each cadaver, cadavers were macerated for $1 \mathrm{~min}$ in their tubes using a plastic pestle. Milli-Q water was added to the macerated cadaver to produce a volume of $1 \mathrm{ml}$ (cadaver + Milli-Q water $=1 \mathrm{ml}$ suspension). From this suspension, 1:100 or $1: 1000$ dilutions were made and virus yield was estimated under a phase contrast microscope using an improved Neubauer brightline haemocytometer.

\subsection{Experiment 2: Effect of short-term feeding on $J A$-induced plants on $O B$ production at equal lethal virus doses}

Since levels of virus-induced mortality differed when virus was ingested on JA-induced and non-induced leaf disks from the Braxton genotype, we measured the yields of OBs that were produced when larvae ingested equal lethal doses on the two plant induction treatments rather than the same numbers of OBs for each larva. We used the estimated lethal dose that killed 50 and $95 \%$ of larvae $\left(\mathrm{LD}_{50}\right.$ and $\left.\mathrm{LD}_{95}\right)$ on JA-induced $\left(\mathrm{LD}_{50}=9929 \mathrm{OB}\right.$, and $\left.\mathrm{LD}_{95}=100,991 \mathrm{OB}\right)$ and noninduced $\left(\mathrm{LD}_{50}=3630 \mathrm{OB}\right.$, and $\left.\mathrm{LD}_{95}=36,919 \mathrm{OB}\right)$ leaf disks in experiment 1 (Table 1 ). There were 90 larvae challenged with the $\mathrm{LD}_{50}, 45-48$ larvae challenged with the $\mathrm{LD}_{95}$, and 21 larvae fed control leaf disks on each plant induction treatment. Larvae in all treatments were virus-challenged at the same time and subsequently maintained on artificial diet as described in experiment 1 . Mortality was recorded and cadavers were collected as described, except that cadavers were weighed at the time of collection, and the numbers of OBs per cadaver were counted. Six cadavers liquefied over the diet before they could be collected and were excluded from the cadaver weight and OB yield analyses. There were two cadavers that were not weighed, but $O B$ yield was counted. There was one cadaver that was weighed, but the $\mathrm{OB}$ count was missing. Time to death for this larva was included in the analysis, since it showed clear signs of virus infection (liquefaction).

The developmental stage of the control larvae $24 \mathrm{~h}$ after being transferred from leaf disk to artificial diet was recorded to assess the impact of leaf disk quality on subsequent development rate. The

Table 1

Lethal dose (OBs larva ${ }^{-1}$ and $95 \%$ confidence intervals) of SfMNPV that killed 50 and $95 \%\left(\mathrm{LD}_{50}\right.$ and $\mathrm{LD}_{95}$, respectively) of $S$. frugiperda larvae, when the virus doses were ingested with JA-induced or non-induced leaf disks from Gasoy and Braxton soybean genotypes (experiment 1). Values were obtained from the final minimal GLM model. Slopes of the mortality-dose relationship were parallel (Fig. 2).

\begin{tabular}{|c|c|c|c|}
\hline & & Gasoy & Braxton \\
\hline \multirow[t]{2}{*}{$\mathrm{LD}_{50}(95 \% \mathrm{CI})$} & Non-induced & $3104(2180-4376)$ & 3630 (2559-5119) \\
\hline & JA-induced & $4282(3028-6027)$ & 9929 (7051-14115) \\
\hline \multirow[t]{4}{*}{$\mathrm{LD}_{95}(95 \% \mathrm{CI})$} & Non-induced & 31574 & 36919 (23782-64066) \\
\hline & & $(20461-54257)$ & \\
\hline & JA-induced & 43558 & 100991 \\
\hline & & $(28040-75733)$ & (63236-183097) \\
\hline
\end{tabular}


number of days to initiate pupation and pupal weights of control insects were also measured. Two control larvae initiated pupation but failed to eclose fully to the pupa, and thus, these larvae were included in time to pupation analysis but not pupal weight.

\subsection{Experiment 3: Effects of long-term feeding on JA-induced plants on $O B$ production and speed of kill}

To determine whether the plant treatment consumed after viruschallenge would impact OB production and speed of kill, we challenged larvae with the highest virus dose used in experiment 1 (30,000 OBs) on JA-induced or non-induced leaf disks, and subsequently reared them until death or pupation on foliage from their respective plant treatments. Foliage from each plant treatment was provided to each larva in individual $30 \mathrm{ml}$ plastic cups lined with moist paper towel. Plants were treated with JA or a control solution in two-day intervals, such that larvae could be provided with new foliage every two days. There were 36 virus-challenged larvae and 9 control larvae per plant treatment. The number of days to initiate pupation and pupal weights of control insects were measured. Mortality was recorded, cadavers were weighed, and the numbers of OBs per cadaver were counted. There was one virus-killed cadaver that was weighed, but the OB count was missing.

\subsection{Statistical analyses}

Experiment 1. We analyzed the dose response mortality of larvae that ingested virus on JA-induced or non-induced leaf disks from the Braxton and Gasoy soybean genotypes together using a generalized linear model (GLM; binomial error distribution and logit link function). The mortality data for Braxton and Gasoy genotypes were previously included as part of a larger-scale dose response analysis on five genotypes in the supplementary materials of Shikano et al. (2017b). Time to death and OB yield measurements were collected from the dose response assays, but were not reported in Shikano et al. (2017b). Time to death was analyzed using a Cox proportional hazards model and $\mathrm{OB}$ yield was analyzed by analysis of covariance (ANCOVA). The lowest two doses from each plant treatment were excluded from time to death and $\mathrm{OB}$ yield analyses due to low sample sizes $(<10$ dead larvae). Soybean genotypes, induction treatment and $\log _{10}$ dose, and their interactions were included as predictor variables. Differences among plant treatments in the relationship between $\mathrm{OB}$ yield and speed of kill were analyzed using multiple linear regression (MLR). OB yield was the response variable and time to death, $\log _{10}$ dose, plant genotype and induction treatment and their interactions were included as predictor variables.

Experiments 2 and 3. An ANCOVA was used to determine differences in the OB yield and cadaver weight. Difference in pupal weight of control insects was also analyzed by ANCOVA. Time to death of viruschallenged larvae and days to pupation of control larvae were analyzed by Cox proportional hazards. The difference in development rate in the first $24 \mathrm{~h}$ after ingesting a JA-induced or non-induced leaf disk was determined by comparing the proportion of larvae that were still in the fourth instar, as opposed to the molting or fifth instar stages, using GLM with Firth bias-adjusted estimates. The change in OB yield with cadaver weight (virus efficiency) was analyzed by MLR with OB yield as the response variable and the plant induction treatment and cadaver weight as predictor variables. The relationship between $\mathrm{OB}$ yield and speed of kill was analyzed by MLR with OB yield as the response variable and the plant induction treatment and time to death as predictor variables. For all of the analyses used in the three experiments, the initial larval weight at the time of virus-challenge was included as a covariate. Sex was also included as a covariate for pupal weight analyses. All nonsignificant interactions were sequentially removed to produce the final minimal model. JMP Pro 12 (SAS Institute, Cary, NC, USA) was used for all analyses.
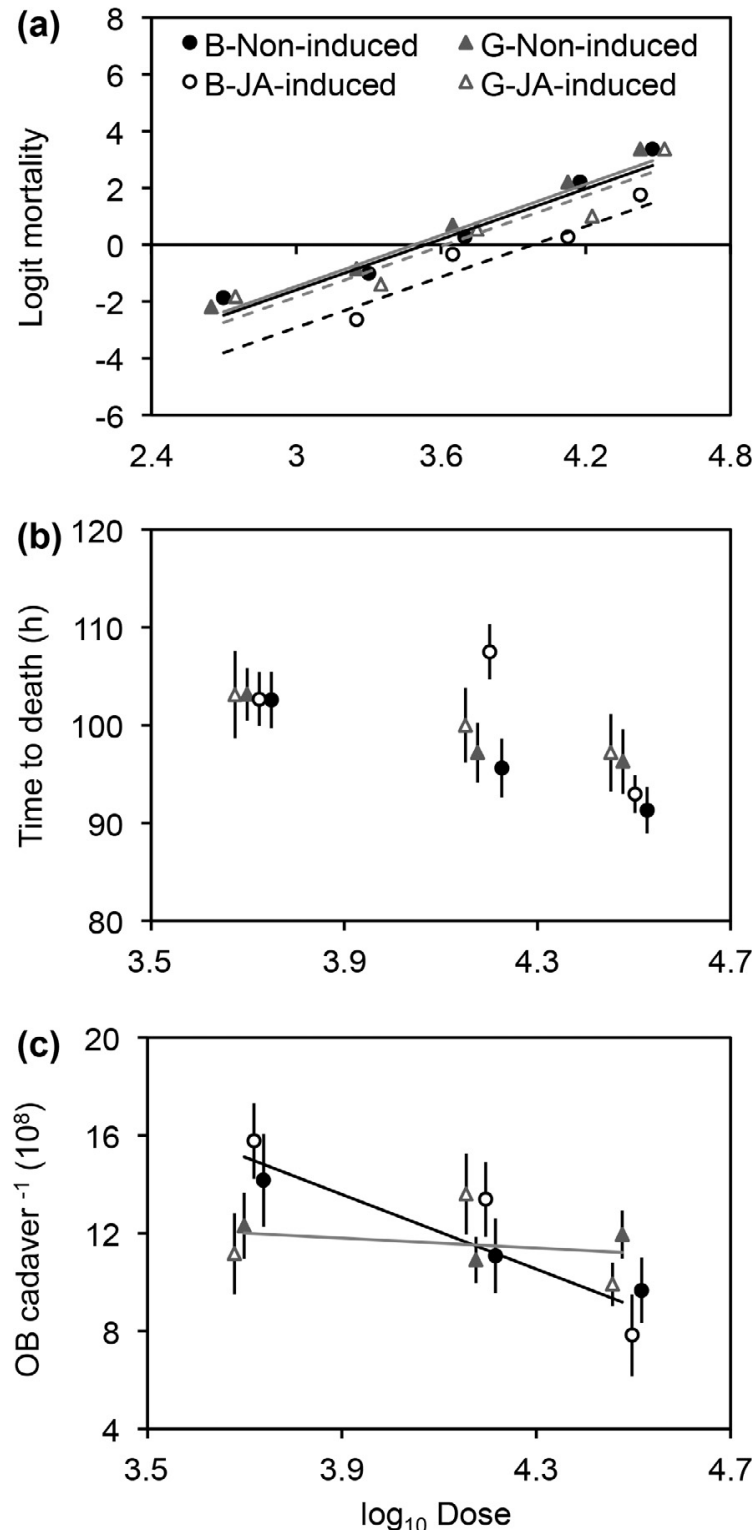

Fig. 2. (a) Logit mortality, (b) time to death and (c) OB yield of larvae challenged with a range of SfMNPV doses on JA-induced or non-induced leaf disks from Braxton or Gasoy soybean genotypes (short-term feeding on plant treatments; experiment 1). Five doses were used to determine logit mortality. Only the highest three doses were used for time to death and OB yield analyses because the two low doses killed fewer than 10 hosts in each plant treatment. Fitted lines represent final minimal models fitted by (a) GLM and (c) ANCOVA. Black lines represent Braxton, grey lines represent Gasoy, solid lines represent non-induced and dashed lines represent JA-induced. No line is available for (b) Cox proportional hazards, though time to death decreased significantly with increasing dose. Symbols are shifted along the $\mathrm{x}$-axis to prevent overlap.

\section{Results}

3.1. Short-term feeding on different quality plants during virus-challenge influenced baculovirus infectivity and $O B$ production (experiment 1)

Mortality of fall armyworm by SfMNPV responded differently to JAinduced defenses in the two soybean genotypes (Fig. 2a; Table 1; genotype by plant induction, $\mathrm{X}_{1}^{2}=3.86, \mathrm{p}=0.049$ ). Virus-induced mortality was significantly lower when the virus was ingested with JA-induced leaf disks than with non-induced leaf disks on the Braxton genotype (paired contrast, $\mathrm{X}_{1}^{2}=16.60, \mathrm{p}<0.0001$ ), but there was no effect of JA-induction on the Gasoy genotype (paired contrast, $\mathrm{X}^{2}{ }_{1}=1.71, \mathrm{p}=0.19$ ). Virus-induced mortality was not significantly 


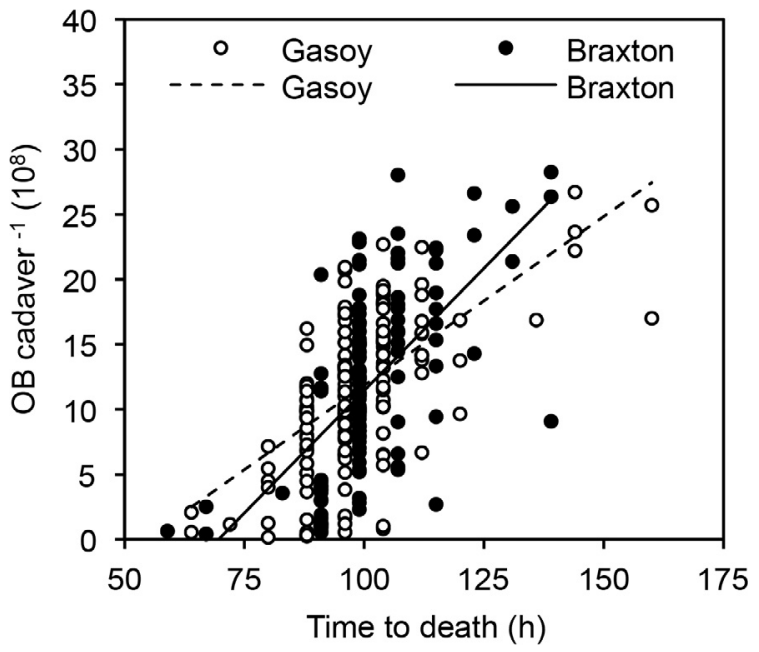

Fig. 3. The trade-off between OB yield and speed of kill when SfMNPV doses were ingested on Braxton or Gasoy soybean genotypes (short-term feeding on plant treatment; experiment 1). Both JA-induced and non-induced plant treatments are included for each genotype. Fitted lines represent the significant interaction between genotype and time to death. Symbols for Braxton are shifted along the $\mathrm{x}$-axis $(+3 \mathrm{~h})$ to prevent overlap. Lines are not shifted.

different between the two genotypes if the leaf disks were not induced (i.e. constitutive plant defenses; paired contrast, $\mathrm{X}^{2}{ }_{1}=0.40, \mathrm{p}=0.53$ ), but mortality was significantly lower for Braxton when both genotypes were JA-induced (paired contrast, $\mathrm{X}^{2}{ }_{1}=11.72, \mathrm{p}<0.001$ ). As expected, mortality increased with virus dose $\left(X^{2}{ }_{1}=270.53\right.$, $\mathrm{p}<0.0001)$. No other interactions between plant induction, genotype and dose were significant.

Virus-challenged armyworms died faster as the dose increased $\left(\mathrm{X}_{1}^{2}=10.94, \mathrm{p}<0.001\right.$; Fig. $\left.2 \mathrm{~b}\right)$, but this response was not affected by plant induction $\left(\mathrm{X}^{2}{ }_{1}=1.83, \mathrm{p}=0.18\right)$ or soybean genotype $\left(\mathrm{X}^{2}{ }_{1}=0.87, \mathrm{p}=0.35\right)$. All other interactions between plant treatment, genotype and dose were non-significant.

The number of OBs produced per cadaver decreased with increasing virus dose $\left(\mathrm{F}_{1,244}=11.02, \mathrm{p}=0.001\right.$; Fig. $\left.2 \mathrm{c}\right)$, likely because cadaver size typically decreases with increasing virus dose (White et al., 2012), though cadaver weight was not measured in this experiment. Dose had a much stronger effect on $\mathrm{OB}$ production when it was ingested with the Braxton genotype than Gasoy (genotype by dose, $\mathrm{F}_{1,244}=6.45$, $\mathrm{p}=0.012)$. At the lower dose $(5000 \mathrm{OB})$, OB yield was higher on Braxton, but at the highest dose (30,000 OB), OB yield was higher on Gasoy. Plant induction did not affect $\mathrm{OB}$ production $\left(\mathrm{F}_{1,244}=0.001\right.$, $\mathrm{p}=0.97)$ and there were no other interactions between plant induction, genotype and dose.

\subsection{Short-term feeding on JA-induced plants during virus-challenge with equivalent lethal doses reduced $O B$ yield (experiment 2)}

Mortality was 68.5 and $72.2 \%$ at the $\mathrm{LD}_{50}$ (JA-induced $=9929 \mathrm{OB}$, non-induced $=3630 \mathrm{OB}$ ) and 97.7 and $97.9 \%$ at the $\mathrm{LD}_{95}$ (JAinduced $=100,991 \mathrm{OB}$, non-induced $=36,919 \mathrm{OB}$ ) when the virus was ingested on JA-induced and non-induced Braxton leaf disks, respectively. As predicted from decreasing $\mathrm{OB}$ yield with increasing virus dose (Fig. 2c), larvae that ingested a higher dose of OBs on JAinduced leaf disks than on non-induced leaf disks to obtain an equal level of mortality, yielded $22 \%$ fewer OBs at the $\mathrm{LD}_{50}\left(\mathrm{~F}_{1,117}=9.32\right.$, $\mathrm{p}=0.003)$, but not at the $\mathrm{LD}_{95}\left(\mathrm{~F}_{1,88}=0.05, \mathrm{p}=0.82\right)$. The lower $\mathrm{OB}$ yield in larvae exposed to an $\mathrm{LD}_{50}$ on JA-induced foliage than on noninduced foliage was associated with a marginally lower cadaver weight (15\% lower) $\left(\mathrm{LD}_{50}, \mathrm{~F}_{1,116}=3.19, \mathrm{p}=0.077\right)$. Plant induction did not significantly affect cadaver weight at the $\mathrm{LD}_{95}\left(\mathrm{~F}_{1,88}=0.50, \mathrm{p}=0.48\right)$ or time to death at the $\mathrm{LD}_{50}\left(\mathrm{X}_{1}^{2}=1.19, \mathrm{p}=0.27\right)$ and $\mathrm{LD}_{95}$
$\left(\mathrm{X}^{2}{ }_{1}=0.14, \mathrm{p}=0.71\right.$ ) (Supplementary material Appendix 1, Fig. S1). The changes in OB yield with speed of kill and cadaver weight, though confounded by different virus doses, are described in Supplementary material Appendix 2.

\subsection{Long-term feeding on JA-induced plants reduced OB yield (experiment} 3)

Mortality did not differ significantly between plant induction treatments when larvae ingested the same virus dose (30,000 OBs larva $^{-1}$ ) on JA-induced or non-induced leaf disks and then subsequently consumed the same plant treatment until death or pupation ( $91.7 \%$ mortality on both treatments). Feeding on JA-induced foliage after virus challenge yielded $44 \%$ fewer OBs per cadaver compared to non-induced foliage $\left(\mathrm{F}_{1,62}=17.61, \mathrm{p}<0.0001\right)$. This coincided with a $31 \%$ lower cadaver weight in infected larvae fed JA-induced than non-induced foliage $\left(\mathrm{F}_{1,63}=10.34, \mathrm{p}=0.002\right)$. Induction treatments did not significantly affect the time to death $\left(\mathrm{X}^{2}{ }_{1}=2.36, \mathrm{p}=0.12\right)$.

\subsection{Plant-mediated effects on the trade-off between $O B$ yield and speed of} kill

We examined if the trade-off between speed of kill and OB yield was influenced by different soybean genotypes and JA-induction at the point of infection (experiment 1). Although the mean OB yield did not significantly differ between genotypes (i.e. no main effect of genotype; $\left.\mathrm{F}_{1,277}=0.72, \mathrm{p}=0.40\right)$, there was an interaction between genotype and time to death $\left(F_{1,277}=6.15, p=0.014\right.$; Fig. 3$)$. If host death occurred quickly, more OBs were produced when the virus was ingested on the Gasoy genotype than Braxton. However, OB yield increased more with longer time to death in larvae fed on Braxton, such that if speed of kill was slow, more OBs were produced on Braxton than Gasoy. The effects of JA-induction $\left(\mathrm{F}_{1,277}=1.52, \mathrm{p}=0.22\right)$ and virus dose $\left(\mathrm{F}_{1,277}=1.13, \mathrm{p}=0.29\right)$ did not significantly affect $\mathrm{OB}$ yield. Additionally, $\mathrm{OB}$ yield was not affected by any interactions between time to death, genotype, JA-induction and dose.

The plant quality (JA-induced or non-induced on Braxton) consumed by virus-infected larvae until death strongly affected the tradeoff between OB yield and speed of kill (experiment 3; Fig. 4a). The longer infected larvae took to die, the more OBs were produced. However, OB yield in larvae that fed on non-induced foliage until death increased more with time to death than those fed JA-induced foliage (plant induction by time to death, $\mathrm{F}_{1,60}=10.38, \mathrm{p}=0.002$ ).

\subsection{Long-term feeding on JA-induced plants reduced virus efficiency (experiment 3)}

As expected, OB yield increased with cadaver weight $\left(F_{1,61}=109.01, p<0.0001\right)$, regardless of the plant treatment consumed until death (experiment 3; Fig. 4b). However, more OBs were produced per unit weight of cadaver if larvae were fed non-induced foliage after virus-challenge than JA-induced foliage $\left(F_{1,61}=7.80\right.$, $\mathrm{p}=0.007)$. There was no interaction between plant treatment and cadaver weight.

\subsection{Long-term feeding on JA-induced plants blocked molting of infected larvae (experiment 3)}

Virus-infected larvae that fed on JA-induced foliage post viruschallenge were significantly more likely to not molt and die in the fourth instar than infected larvae that fed on non-induced foliage $\left(\mathrm{X}_{1}^{2}=8.39, \mathrm{p}=0.004 ; 11\right.$ out of 33 cadavers and 2 out of 33 cadavers were fourth instars on JA-induced and non-induced foliage, respectively). All other lethally infected larvae died in the fifth instar. 

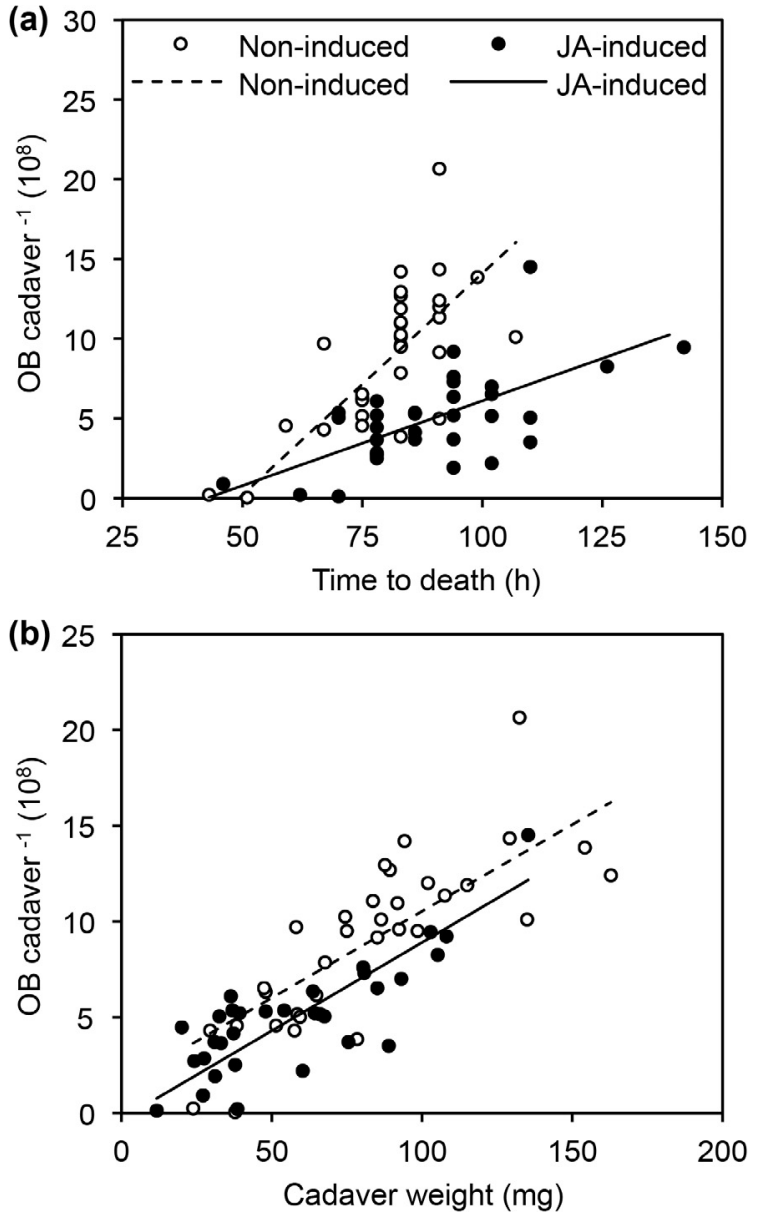

Fig. 4. (a) The trade-off between OB yield and speed of kill and (b) relationship between $\mathrm{OB}$ yield and cadaver weight (i.e. virus efficiency) when larvae ingested the same SfMNPV dose (30000 OB) on JA-induced or non-induced Braxton leaf disks, and were subsequently reared until death on the same plant treatments (long-term feeding on plant treatments; experiment 3). Fitted lines represent (a) the significant interaction between JA-induction and time to death, and (b) the significant main effect of JA-induction. (a) Symbols for JA-induced are shifted along the $\mathrm{x}$-axis $(+3 \mathrm{~h})$ to prevent overlap. Lines are not shifted.

\subsection{Effects of short and long-term feeding on JA-induced plants on larval development}

Control larvae (unchallenged larvae from experiment 2) tended to develop more slowly in the first $24 \mathrm{~h}$ on artificial diet following the ingestion of a JA-induced leaf disk compared to a non-induced leaf disk (Fig. 5a; $\mathrm{X}_{1}^{2}=3.24, \mathrm{p}=0.072$ ). However, this short-term exposure to the plant treatments had no significant impact on time to pupation (Fig. $5 \mathrm{~b} ; \mathrm{X}^{2}{ }_{1}=0.22, \mathrm{p}=0.64$ ) or pupal weight (Fig. $5 \mathrm{c}$; $\mathrm{F}_{1,37}=0.67$, $\mathrm{p}=0.42$ ).

Control larvae (unchallenged larvae from experiment 3) developed slower in the first $24 \mathrm{~h}$ on JA-induced foliage following the ingestion of a JA-induced leaf disk compared to larvae that fed on non-induced foliage after ingesting a non-induced leaf disk (Fig. 5a; $\mathrm{X}_{1}^{2}=6.85$, $\mathrm{p}=0.009$ ). Larvae that were fed JA-induced foliage after a JA-induced leaf disk took $40 \%$ longer to reach pupation (Fig. $5 \mathrm{~b} ; \mathrm{X}^{2}{ }_{1}=8.40$, $\mathrm{p}=0.004)$ and produced pupae that were $27 \%$ lighter than larvae that fed on non-induced leaf disk and foliage (Fig. $5 \mathrm{c} ; \mathrm{F}_{1,14}=36.51$, $\mathrm{p}<0.0001)$.

\section{Discussion}

In this study, we used the Braxton soybean genotype, which lowered virus-induced lethality when induced by JA, and the Gasoy genotype, which did not. We demonstrated that short-term feeding of larvae on JA-induced foliage at the point of virus ingestion had no impact on virus $\mathrm{OB}$ production, regardless of the soybean genotype's effect on lethality by virus (experiment 1 ). When larvae ingested a high virus dose $(30,000 \mathrm{OB})$ and fed on foliage until death or pupation (long-term feeding; experiment 3), there was no difference in mortality between larvae that fed on JA-induced or non-induced foliage. This was not surprising given that induced plant defenses usually do not affect virus efficacy as much at high virus doses compared to low and moderate doses (Hoover et al., 1998a). Interestingly, long-term feeding by virusinfected larvae on JA-induced soybean foliage until death, which is more representative of field conditions, significantly reduced the number of OBs produced (experiment 3). These findings suggest that plant-mediated effects on virus infectivity and yield can depend on virus dose and the timing and duration of consuming plants of different quality.

We hypothesized that infected larvae would grow slower on JAinduced than non-induced foliage and consequently produce fewer virus OBs because baculovirus infection can result in a large-scale shutdown of protein synthesis in the host (Choi et al., 2012; Jakubowska et al., 2013; Salem et al., 2011), including the downregulation of genes involved in detoxification and digestive functions (Noland et al., 2013). Our findings both support and contradict this hypothesis. First, the weights of cadavers of infected larvae on JAinduced foliage were reduced by $31 \%$ compared to the cadavers of infected larvae on non-induced foliage. Concurrently, the pupal weights of uninfected (control) larvae were reduced by almost the same amount on JA-induced foliage compared to non-induced foliage (27\% lower). This suggests that virus infection did not exacerbate poorer growth on JA-induced foliage. In fact, infected larvae on JA-induced foliage achieved the final (cadaver) weight at the same time as those on noninduced foliage (equal time to death). In contrast, uninfected (control) larvae took longer to reach pupation on JA-induced foliage than on non-induced foliage. This indicates that infected larvae on JA-induced foliage grew faster than uninfected larvae, relative to their counterparts on non-induced foliage. The growth of infected larvae may have been faster than uninfected larvae on JA-induced foliage because many of the infected larvae (33\%) were blocked from molting into the next (fifth) instar. Baculoviruses express a gene (ecdysteroid UDP-glucosyltransferase (egt) gene) that increases the amount of host tissue that can be converted into virus OBs by blocking molting (O'Reilly and MIller, 1989), thereby prolonging host feeding and increasing body mass (Cory et al., 2004). Thus, continued host growth is assumed to be highly favorable for virus fitness. However, the majority of infected larvae on non-induced foliage were able to molt into the next instar (94\%), which actually benefited growth and $\mathrm{OB}$ production. It appears that the slower development of infected larvae on JA-induced foliage may have allowed the egt gene to block molting, which was detrimental for $\mathrm{OB}$ yield. Thus, the value of the virus' ability to block host molting may depend on host food quality. Timing may also be important, since blocking pupation would clearly benefit host growth and OB production regardless of food quality (Cory et al., 2004).

The dynamics of insect-pathogen interactions are determined primarily by insect and pathogen density, transmission and virulence (Myers and Cory, 2016). The extent to which induced plant defenses affect baculovirus epizootics may depend on herbivore density and its effects on food plant availability, virus transmission and virus yield. Mobile insect herbivores, such as fall armyworms, at low densities with an abundance of food plants are likely to move within and among plants (Pannuti et al., 2016), in part to avoid consuming induced foliage. There is also usually a time lag between ingestion of foliage and induced plant responses, such that an insect can feed for a period of time before it needs to deal with induced defenses (Underwood, 1998). Thus, induced defenses are more likely to be a factor in baculovirus infections when the density of the insect population reaches a point where most of the plant population is under attack and induced. Under 
this scenario, our findings suggest that induced plant defenses may limit the number of OBs released for the next round of horizontal transmission by reducing OB yield. Moreover, since plant induction lowers virus-induced mortality on some soybean genotypes, there may be an additive effect whereby plant induction results in fewer OBs being released and subsequent susceptible larvae needing to consume more OBs to become infected. Thus, the plant via induction may indirectly weaken host-pathogen transmission dynamics. On the other hand, slower larval growth on induced plants could permit more rounds of infection in a host generation. Our infected fourth instars maintained on JA-induced and non-induced foliage died in approximately 3.6 and 3.3 days ( 86.6 and $80.3 \mathrm{~h}$ ), respectively, while unchallenged (control) larvae took 7.3 and 5.2 days to reach pupation on the respective plant treatments. This indicates that OBs released from cadavers on JAinduced plants would still have 3.7 days to cause a second round of infection among the same cohort of insects, compared to only 1.9 days on non-induced plants. Since lepidopteran larvae become more resistant to baculoviruses as they age (i.e. developmental resistance) (Engelhard and Volkman, 1995), armyworms that are 3.7 days from reaching pupation on JA-induced plants would be younger and more susceptible than larvae on non-induced plants. Together these results suggest that the effects of induced plant defenses on baculovirus fitness in natural populations is complex, varying with the interactions between plant-mediated effects on virus transmission and yield and insect growth rate.

We found that $\mathrm{OB}$ yield decreased with increasing virus dose when the virus was ingested on the Braxton genotype, but this relationship was significantly weaker on the Gasoy genotype. Virus genotypes have been shown to vary in their production of OBs with dose (Cory and Myers, 2004), but this is the first time that intraspecific variation in plants has been demonstrated to alter this relationship. Whether insects in nature are more likely to ingest higher or lower baculovirus doses is debatable. Since OBs are released from cadavers, the spatial distribution of OBs on plants is patchy. Spatial clumping of virus inoculum, along with variation in host densities and differences in feeding behaviour and susceptibility among larval instars, contribute to a non-linear transmission of baculoviruses (D'Amico et al., 2005; Dwyer, 1991). At low insect population densities, the risk of ingesting freshly virus-killed cadavers should be low. Most of the OBs within these cadavers may get washed away by rain or inactivated by ultraviolet radiation before being ingested by potential hosts. Some insects may also avoid ingesting high doses of virus by avoiding viruskilled cadavers (Parker et al., 2010). Thus, our data suggest that at low insect densities where insects are more likely to ingest lower virus doses, more OBs will be released into the environment by insects infected on the Braxton genotype. Larger patches of baculovirus inoculum (i.e. higher yield of OBs per cadaver) have been shown to induce higher mortality in the following host generation on the same plants, even when fewer patches were present (Hesketh and Hails, 2015). This suggests that virus persistence may be greater on the Braxton genotype at low insect densities, but that the intensity of epizootics at high insect densities, where insects may encounter higher doses (i.e. more cadavers), may be greater on the Gasoy genotype where more OBs are produced at high doses than on Braxton.

Consumption of JA-induced foliage by infected larvae significantly reduced the degree to which $\mathrm{OB}$ yield increased with time to death. This was in part due to lower larval weights at death on JA-induced foliage, but also because the virus produced fewer OBs per unit of host tissue in these larvae (Fig. 4b). This reduction in tissue conversion efficiency of the virus on JA-induced foliage might result from toxic effects on the host that reduces the nutritive quality of the host for the virus. Virus efficiency may also be influenced by plant-mediated changes in insect immune functioning (Bukovinszky et al., 2009; Klemola et al., 2007; Shikano et al., 2015, 2010). Toxic phytochemicals ingested by host insects have been shown to reduce the germination of pathogenic fungal conidia (Gallardo et al., 1990; Poprawski et al., 2000) and the growth and
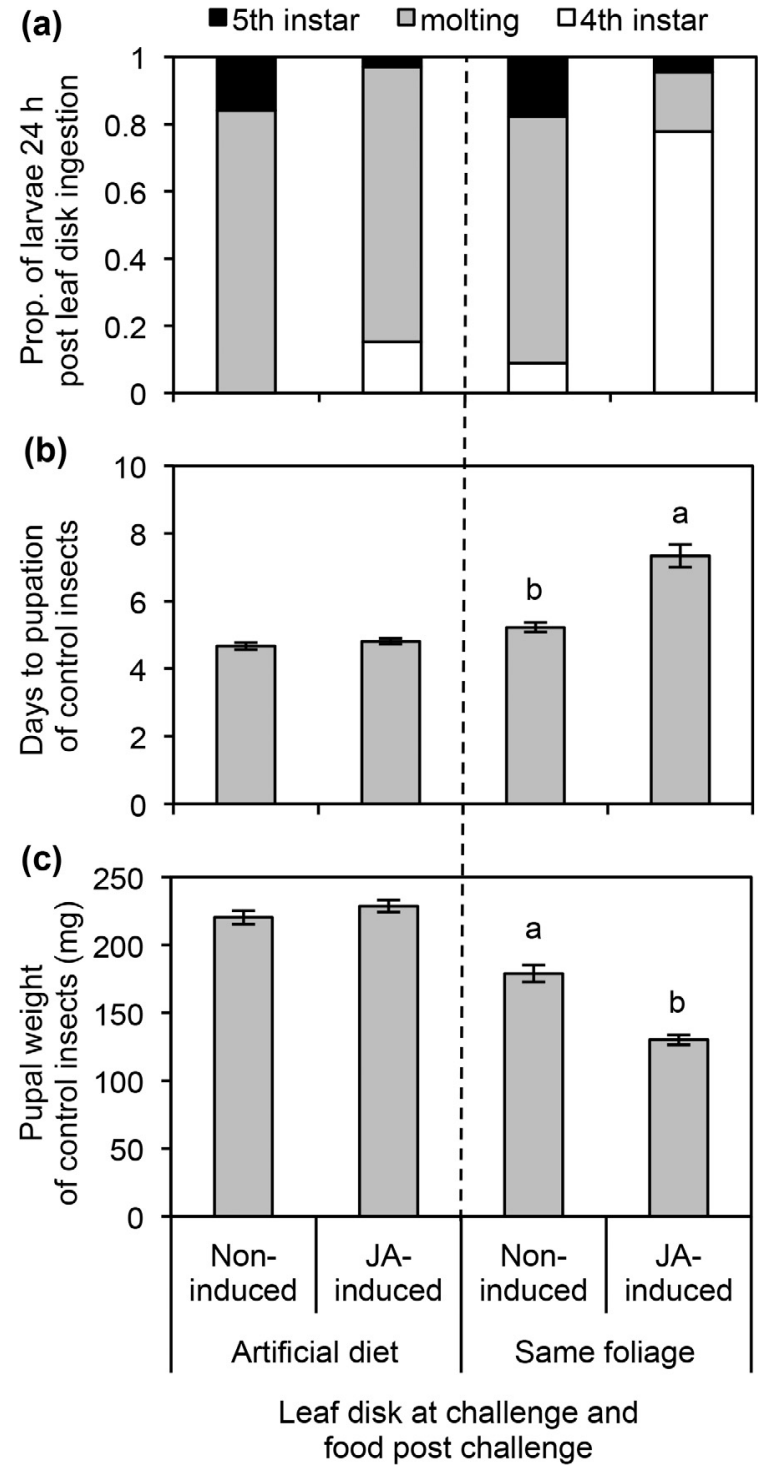

Fig. 5. (a) Proportion of larvae in each developmental stage (4th instar, molting from 4th to 5 th instar or already in the 5th instar) $24 \mathrm{~h}$ after ingesting a JA-induced or non-induced leaf disk, not treated with SfMNPV. (b) Days to pupation and (c) pupal weight of control larvae that ingested a JA-induced or non-induced leaf disk. Bars to the left of the dashed line represent larvae that were fed artificial diet after ingesting the entire leaf disk (experiment 2; short-term feeding on plant treatments). Bars on the right represent larvae that were maintained on the same plant treatment until pupation (experiment 3; longterm feeding on plant treatments). Different letters above bars indicate significant difference $(\mathrm{p}<0.05)$.

survival of parasitoid larvae (Barbosa et al., 1986; Campbell and Duffey, 1979; Lampert et al., 2011; Lampert and Bowers, 2013). Some toxic phytochemicals can pass into the haemolymph of non-sequestering insects (e.g. Lampert et al., 2011), but whether these phytochemicals or their metabolites could directly influence virus replication in cell nuclei or inhibit enzymes involved in virus replication is unknown. Moreover, our findings indicate that the plant genotype ingested with the virus can also influence the slope of the time to death and virus yield relationship (Fig. 3). We do not know the mechanism behind these differences, but it may be associated with higher phenolic content in Braxton than Gasoy (Shikano et al., 2017b) and the relationship between high phenolic content and reduced virus efficacy (Felton and Duffey, 1990; Hoover et al., 1998b; Shikano et al., 2017b). The trade-off between OB yield and speed of kill has been shown to vary with the plant species that was ingested with the virus and the plant species that the virus was collected from (i.e. virus isolate) (Raymond et al., 2002). 
With only a handful of studies that have examined plant-mediated effects on production of entomopathogen progeny, it is difficult to explain why virus yield and its relationship with speed of kill and cadaver weight differ with intraspecific variation in plant quality. One possibility is plant-mediated changes to the outcome of competition among virus genotypes within the host. Lepidopteran-specific nucleopolyhedroviruses (Alphabaculovirus; genera of baculovirus used in our study) have a unique morphology whereby many virions, each of which can contain multiple genotypes, are embedded in a proteinaceous matrix (i.e. OB). Studies that have isolated individual virus genotypes have demonstrated that individual genotypes vary in their infectivity, speed of kill and yield (Hodgson et al., 2004, 2002, 2001; Redman et al., 2016). Moreover, the plant species fed on by hosts during infection have been shown to differentially select virus genotypes (Hodgson et al., 2004, 2002). Ali et al. (2002) found that the infectivity of Helicoverpa zea single nucleocapsid NPV (HzSNPV) OBs collected from killed hosts that were fed vegetative plant parts were more than two times more infectious than OBs collected from hosts fed reproductive parts. Thus, more virulent genotypes may have been selected when hosts fed on vegetative tissue, suggesting that intraspecific variation in plant quality might influence competition among virus genotypes within the host, and thereby play a role in maintaining the genetic diversity of baculoviruses. Regardless of how plant genotype and induced anti-herbivore defenses influenced key components of baculovirus fitness in our study, it highlights the importance of bottom-up effects, even at the individual plant level, and the complexity of interactions that may determine pathogen fitness in field populations.

\section{Acknowledgements}

We thank Morgan Kimmel for laboratory assistance. This work was funded by a National Science Foundation (NSF) Grant 1316334 to K.H. and B.D.E. as part of the joint NSF-NIH-USDA Ecology and Evolution of Infectious Diseases program.

\section{Appendix A. Supplementary material}

Supplementary data associated with this article can be found, in the online version, at http://dx.doi.org/10.1016/j.jip.2017.05.001.

\section{References}

Adams, A.S., Aylward, F.O., Adams, S.M., Erbilgin, N., Aukema, B.H., Currie, C.R., Suen, G., Raffa, K.F., 2013. Mountain pine beetles colonizing historical and naive host trees are associated with a bacterial community highly enriched in genes contributing to terpene metabolism. Appl. Environ. Microbiol. 79, 3468-3475. http://dx.doi.org/10. 1128/AEM.00068-13.

Ali, M.I., Felton, G.W., Meade, T., Young, S.Y., 1998. Influence of interspecific and intraspecific host plant variation on the susceptibility of Heliothines to a baculovirus. Biol. Control 12, 42-49. http://dx.doi.org/10.1006/bcon.1998.0619.

Ali, M.I., Young, S.Y., Felton, G.W., McNew, R.W., 2002. Influence of the host plant on occluded virus production and lethal infectivity of a baculovirus. J. Invertebr. Pathol. 81, 158-165.

Anderson, R.M., May, R.M., 1981. The population dynamics of microparasites and their invertebrate hosts. Philos. Trans. R. Soc. B Biol. Sci. 291, 451-524. http://dx.doi.org/ 10.1098/rstb.1981.0005.

Barbosa, P., Saunders, J.A., Kemper, J., Trumbule, R., Olechno, J., Martinat, P., 1986. Plant allelochemicals and insect parasitoids effects of nicotine on Cotesia congregata (Say) (Hymenoptera: Braconidae) and Hyposoter annulipes (Cresson) (Hymenoptera: Ichneumonidae). J. Chem. Ecol. 12, 1319-1328. http://dx.doi.org/10.1007/ BF01012351.

Biere, A., Bennett, A.E., 2013. Three-way interactions between plants, microbes and insects. Funct. Ecol. 27, 567-573. http://dx.doi.org/10.1111/1365-2435.12100.

Biere, A., Tack, A.J.M., 2013. Evolutionary adaptation in three-way interactions between plants, microbes and arthropods. Funct. Ecol. 27, 646-660. http://dx.doi.org/10. $1111 / 1365-2435.12096$.

Bukovinszky, T., Poelman, E.H., Gols, R., Prekatsakis, G., Vet, L.E.M., Harvey, J.A., Dicke, M., 2009. Consequences of constitutive and induced variation in plant nutritional quality for immune defence of a herbivore against parasitism. Oecologia 160, 299-308. http://dx.doi.org/10.1007/s00442-009-1308-y.

Campbell, B.C., Duffey, S.S., 1979. Tomatine and parasitic wasps: potential incompatibility of plant antibiosis with biological control. Science 205, 700-702.

Choi, J.Y., Roh, J.Y., Wang, Y., Zhen, Z., Tao, X.Y., Lee, J.H., Liu, Q., Kim, J.S., Shin, S.W.,
Je, Y.H., 2012. Analysis of genes expression of Spodoptera exigua larvae upon AcMNPV infection. PLoS One 7, e42462. http://dx.doi.org/10.1371/journal.pone.0042462.

Chung, S.H., Rosa, C., Scully, E.D., Peiffer, M., Tooker, J.F., Hoover, K., Luthe, D.S., Felton, G.W., 2013. Herbivore exploits orally secreted bacteria to suppress plant defenses. Proc. Natl. Acad. Sci. 110, 15728-15733. http://dx.doi.org/10.1073/pnas. 1308867110.

Cory, J.S., Clarke, E.E., Brown, M.L., Hails, R.S., O’Reilly, D.R., 2004. Microparasite manipulation of an insect: the influence of the egt gene on the interaction between a baculovirus and its lepidopteran host. Funct. Ecol. 18, 443-450. http://dx.doi.org/ 10.1111/j.0269-8463.2004.00853.x.

Cory, J.S., Hoover, K., 2006. Plant-mediated effects in insect-pathogen interactions. Trends Ecol. Evol. 21, 278-286. http://dx.doi.org/10.1016/j.tree.2006.02.005.

Cory, J.S., Myers, J.H., 2004. Adaptation in an insect host-plant pathogen interaction. Ecol. Lett. 7, 632-639. http://dx.doi.org/10.1111/j.1461-0248.2004.00617.x.

Cory, J.S., Myers, J.H., 2003. The ecology and evolution of insect baculoviruses. Annu. Rev. Ecol. Evol. Syst. 34, 239-272. http://dx.doi.org/10.1146/132402.

D'Amico, V., Elkinton, J.S., Podgwaite, J.D., Buonaccorsi, J.P., Dwyer, G., 2005. Pathogen clumping: an explanation for non-linear transmission of an insect virus. Ecol. Entomol. 30, 383-390. http://dx.doi.org/10.1111/j.0307-6946.2005.00697.x.

Douglas, A.E., 2015. Multiorganismal insects: diversity and function of resident microorganisms. Annu. Rev. Entomol. 60, 17-34. http://dx.doi.org/10.1146/ annurev-ento-010814-020822.

Dwyer, G., 1991. The roles of density, stage, and patchiness in the transmission of an insect virus. Ecology 72, 559-574. http://dx.doi.org/10.2307/2937196.

Elderd, B.D., Rehill, B.J., Haynes, K.J., Dwyer, G., 2013. Induced plant defenses, hostpathogen interactions, and forest insect outbreaks. Proc. Natl. Acad. Sci. 110, 14978-14983. http://dx.doi.org/10.1073/pnas.1300759110.

Elderd, B.D., Reilly, J.R., 2014. Warmer temperatures increase disease transmission and outbreak intensity in a host-pathogen system. J. Anim. Ecol. 83, 838-849. http://dx. doi.org/10.1111/1365-2656.12180.

Engelhard, E.K., Volkman, L.E., 1995. Developmental resistance in fourth instar Trichoplusia ni orally inoculated with Autographa californica M nuclear polyhedrosis virus. Virology 209, 384-389.

Farrar, R.R., Ridgway, R.L., 2000. Host plant effects on the activity of selected nuclear polyhedrosis viruses against the corn earworm and beet armyworm (Lepidoptera: Noctuidae). Environ. Entomol. 29, 108-115. http://dx.doi.org/10.1603/0046-225X29.1.108.

Felton, G.W., Duffey, S.S., 1990. Inactivation of baculovirus by quinones formed in insectdamaged plant tissues. J. Chem. Ecol. 16, 1221-1236. http://dx.doi.org/10.1007/ BF01021021.

Frago, E., Dicke, M., Godfray, H.C.J., 2012. Insect symbionts as hidden players in insectplant interactions. Trends Ecol. Evol. 27, 705-711. http://dx.doi.org/10.1016/j.tree. 2012.08.013.

Fuxa, J.R., 2004. Ecology of insect nucleopolyhedroviruses. Agric. Ecosyst. Environ. 103, 27-43. http://dx.doi.org/10.1016/j.agee.2003.10.013.

Gallardo, F., Boethel, D.J., Fuxa, J.R., Richter, A., 1990. Susceptibility of Heliothis zea (Boddie) larvae to Nomuraea rileyi (Farlow) Samson: effects of alpha-tomatine at the third trophic level. J. Chem. Ecol. 16, 1751-1759. http://dx.doi.org/10.1007/ BF01020492.

Hansen, A.K., Moran, N.A., 2014. The impact of microbial symbionts on host plant utilization by herbivorous insects. Mol. Ecol. 23, 1473-1496. http://dx.doi.org/10. $1111 / \mathrm{mec} .12421$.

Hesketh, H., Hails, R.S., 2015. Bacillus thuringiensis impacts on primary and secondary baculovirus transmission dynamics in Lepidoptera. J. Invertebr. Pathol. 132, 171-181. http://dx.doi.org/10.1016/j.jip.2015.09.008.

Hodgson, D.J., Hitchman, R.B., Vanbergen, A.J., Hails, R.S., Possee, R.D., Cory, J.S., 2004. Host ecology determines the relative fitness of virus genotypes in mixedgenotype nucleopolyhedrovirus infections. J. Evol. Biol. 17, 1018-1025. http://dx. doi.org/10.1111/j.1420-9101.2004.00750.x.

Hodgson, D.J., Vanbergen, A.J., Hartley, S.E., Hails, R.S., Cory, J.S., 2002. Differential selection of baculovirus genotypes mediated by different species of host food plant. Ecol. Lett. 5, 512-518. http://dx.doi.org/10.1046/j.1461-0248.2002.00338.x.

Hodgson, D.J., Vanbergen, A.J., Watt, A.D., Hails, R.S., Cory, J.S., 2001. Phenotypic variation between naturally co-existing genotypes of a Lepidopteran baculovirus. Evol. Ecol. Res. 3, 687-701.

Hoover, K., Stout, M.J., Alaniz, S.A., Hammock, B.D., Duffey, S.S., 1998a. Influence of induced plant defenses in cotton and tomato on the efficacy of baculoviruses on noctuid larvae. J. Chem. Ecol. 24, 253-271.

Hoover, K., Yee, J.L., Schultz, C.M., Rocke, D.M., Hammock, B.D., Duffey, S.S., 1998b. Effects of plant identity and chemical constituents on the efficacy of a baculovirus against Heliothis virescens. J. Chem. Ecol. 24, 221-252.

Jakubowska, A.K., Vogel, H., Herrero, S., 2013. Increase in gut microbiota after immune suppression in baculovirus-infected larvae. PLoS Pathog. 9, e1003379. http://dx.doi. org /10.1371/journal.ppat.1003379.

Keating, S.T., Yendol, W.G., Schultz, J.C., 1988. Relationship between susceptibility of gypsy moth larvae (Lepidoptera: Lymantriidae) to a baculovirus and host plant foliage constituents. Environ. Entomol. 17, 952-958.

Klemola, N., Klemola, T., Rantala, M.J., Ruuhola, T., 2007. Natural host-plant quality affects immune defence of an insect herbivore. Entomol. Exp. Appl. 123, 167-176. http://dx.doi.org/10.1111/j.1570-7458.2007.00533.x.

Kouassi, K.C., Lorenzetti, F., Guertin, C., Cabana, J., Mauffette, Y., 2001. Variation in the susceptibility of the forest tent caterpillar (Lepidoptera: Lasiocampidae) to Bacillus thuringiensis variety kurstaki HD-1: effect of the host plant. J. Econ. Entomol. 94, 1135-1141. http://dx.doi.org/10.1603/0022-0493-94.5.1135.

Lampert, E.C., Bowers, M.D., 2013. Detrimental effects of plant compounds on a polyembryonic parasitoid are mediated through its highly polyphagous herbivore 
host. Entomol. Exp. Appl. 148, 267-274. http://dx.doi.org/10.1111/eea.12093.

Lampert, E.C., Zangerl, A.R., Berenbaum, M.R., Ode, P.J., 2011. Generalist and specialist host-parasitoid associations respond differently to wild parsnip (Pastinaca sativa) defensive chemistry. Ecol. Entomol. 36, 52-61. http://dx.doi.org/10.1111/j.13652311.2010.01244.x.

Mason, C.J., Couture, J.J., Raffa, K.F., 2014. Plant-associated bacteria degrade defense chemicals and reduce their adverse effects on an insect defoliator. Oecologia 175, 901-910. http://dx.doi.org/10.1007/s00442-014-2950-6.

Myers, J.H., Cory, J.S., 2016. Ecology and evolution of pathogens in natural populations of Lepidoptera. Evol. Appl. 9, 231-247. http://dx.doi.org/10.1111/eva.12328.

Noland, J.E., Breitenbach, J.E., Popham, H.J.R., Hum-Musser, S.M., Vogel, H., Musser, R.O., 2013. Gut transcription in Helicoverpa zea is dynamically altered in response to baculovirus infection. Insects 4, 506-520. http://dx.doi.org/10.3390/ insects4030506.

O'Reilly, D.R., MIller, L.K., 1989. A baculovirus blocks insect molting by producing ecdysteroid UDP-glucosyl transferase. Science 245, 1110-1112.

Ownley, B.H., Gwinn, K.D., Vega, F.E., 2010. Endophytic fungal entomopathogens with activity against plant pathogens: ecology and evolution. BioControl 55, 113-128. http://dx.doi.org/10.1007/s10526-009-9241-x.

Pannuti, L.E.R., Paula-Moraes, S.V., Hunt, T.E., Baldin, E.L.L., Dana, L., Malaquias, J.V., 2016. Plant-to-plant movement of Striacosta albicosta (Lepidoptera: Noctuidae) and Spodoptera frugiperda (Lepidoptera: Noctuidae) in maize (Zea mays). J. Econ. Entomol. 109, 1125-1131. http://dx.doi.org/10.1093/jee/tow042.

Parker, B.J., Elderd, B.D., Dwyer, G., 2010. Host behaviour and exposure risk in an insectpathogen interaction. J. Anim. Ecol. 79, 863-870. http://dx.doi.org/10.1111/j.13652656.2010.01690.x.

Pineda, A., Zheng, S.J., van Loon, J.J.A., Pieterse, C.M.J., Dicke, M., 2010. Helping plants to deal with insects: the role of beneficial soil-borne microbes. Trends Plant Sci. 15, 507-514. http://dx.doi.org/10.1016/j.tplants.2010.05.007.

Poprawski, T.J., Greenberg, S.M., Ciomperlik, M.A., 2000. Effect of host plant on Beauveria bassiana- and Paecilomyces fumosoroseus-induced mortality of Trialeurodes vaporariorum (Homoptera: Aleyrodidae). Environ. Entomol. 29, 1048-1053. http:// dx.doi.org/10.1603/0046-225X-29.5.1048.

Raymond, B., Hails, R.S., 2007. Variation in plant resource quality and the transmission and fitness of the winter moth, Operophtera brumata nucleopolyhedrovirus. Biol. Control 41, 237-245. http://dx.doi.org/10.1016/j.biocontrol.2007.02.005.

Raymond, B., Hartley, S.E., Cory, J.S., Hails, R.S., 2005. The role of food plant and pathogen-induced behaviour in the persistence of a nucleopolyhedrovirus. J. Invertebr. Pathol. 88, 49-57. http://dx.doi.org/10.1016/j.jip.2004.09.005.
Raymond, B., Vanbergen, A., Pearce, I., Hartley, S.E., Cory, J.S., Hails, R.S., 2002. Host plant species can influence the fitness of herbivore pathogens: the winter moth and its nucleopolyhedrovirus. Oecologia 131, 533-541. http://dx.doi.org/10.1007/s00442 002-0926-4.

Redman, E.M., Wilson, K., Cory, J.S., 2016. Trade-offs and mixed infections in an obligate-killing insect pathogen. J. Anim. Ecol. 85, 1200-1209. http://dx.doi.org/10 1111/1365-2656.12547.

Salem, T.Z., Zhang, F., Xie, Y., Thiem, S.M., 2011. Comprehensive analysis of host gene expression in Autographa californica nucleopolyhedrovirus-infected Spodoptera frugiperda cells. Virology 412, 167-178. http://dx.doi.org/10.1016/j.virol.2011.01. 006.

Shikano, I., Ericsson, J.D., Cory, J.S., Myers, J.H., 2010. Indirect plant-mediated effects on insect immunity and disease resistance in a tritrophic system. Basic Appl. Ecol. 11, 15-22. http://dx.doi.org/10.1016/j.baae.2009.06.008.

Shikano, I., Olson, G.L., Cory, J.S., 2015. Impact of non-pathogenic bacteria on insect disease resistance: importance of ecological context. Ecol. Entomol. 40, 620-628. http://dx.doi.org/10.1111/een.12235.

Shikano, I., Rosa, C., Tan, C.-W., Felton, G.W., 2017a. Tritrophic interactions: microbemediated plant effects on insect herbivores. Annu. Rev. Phytopathol. http://dx.doi. org/10.1146/annurev-phyto-080516-035319.

Shikano, I., Shumaker, K., Peiffer, M., Felton, G.W., Hoover, K., 2017b. Plant-mediated effects on an insect-pathogen interaction vary with intraspecific genetic variation in plant defences. Oecologia. http://dx.doi.org/10.1007/s00442-017-3826-3.

Tack, A.J.M., Dicke, M., 2013. Plant pathogens structure arthropod communities across multiple spatial and temporal scales. Funct. Ecol. 27, 633-645. http://dx.doi.org/10. 1111/1365-2435.12087.

Thaler, J.S., Stout, M.J., Karban, R., Duffey, S.S., 1996. Exogenous jasmonates simulate insect wounding in tomato plants (Lycopersicon esculentum) in the laboratory and field. J. Chem. Ecol. 22, 1767-1781. http://dx.doi.org/10.1007/BF02028503.

Underwood, N., 1998. The timing of induced resistance and induced susceptibility in the soybean-Mexican bean beetle system. Oecologia 114, 376-381.

White, S.M., Burden, J.P., Maini, P.K., Hails, R.S., 2012. Modelling the within-host growth of viral infections in insects. J. Theor. Biol. 312, 34-43. http://dx.doi.org/10.1016/j. jtbi.2012.07.022.

Wilson, K.R., O'Reilly, D.R., Hails, R.S., Cory, J.S., 2000. Age-related effects of the Autographa californica multiple nucleopolyhedrovirus egt gene in the cabbage looper (Trichoplusia ni). Biol. Control 19, 57-63. http://dx.doi.org/10.1006/bcon.2000 0841. 